\title{
Inoculação e reinoculação de Herbaspirillum seropedicae em duas variedades de arroz irrigado
}

\author{
Inoculation and reinoculation of the Herbaspirillum seropedicae in two rice lowland varieties \\ Inoculación y reinoculación de Herbaspirillum seropedicae en dos variedades de arroz de tierras \\ bajas
}

Recebido: 24/11/2021 | Revisado: 01/12/2021 | Aceito: 06/12/2021 | Publicado: 16/12/2021

ORCID: https://orcid.org/0000-0001-7324-969X
Universidade Estadual do Sudoeste da Bahia, Brasil
E-mail: joilsonferreira@ @esb.edu.br
Rayka Kristian Alves Santos
ORCID: https://orcid.org/0000-0003-2232-8288
Eniversidade Estadual do Sudoeste da Bahia, Brasil
E-mail:raykakristian@ yahoo.com.br
Maida Cynthia Duca de Lima
ORCID: https://orcid.org/0000-0002-9946-1258
Universidade Estadual do Sudoeste da Bahia, Brasil
E-mail:maidaflorestal @ gmail.com
Mariana dos Santos Nascimento
ORCID: https://orcid.org/0000-0001-9826-137X
Universidade Estadual do Sudoeste da Bahia, Brasil
E-mail:nascimentoms30@ gmail.com
Joseani Santos Ávila
ORCID: https://orcid.org/0000-0002-4345-9976
Universidade Estadual do Sudoeste da Bahia, Brasil
E-mail:joseanis.avila@ gmail.com
Roger Luiz da Silva Almeida Filho
ORCID: https://orcid.org/0000-0003-0400-006X
Universidade Estadual do Sudoeste da Bahia, Brasil
E-mail:rogerluizfilho@ gmail.com
Vera Lúcia Divan Baldani

\begin{abstract}
Resumo
O estudo consistiu em avaliar o efeito da inoculação e reinoculação da estirpe ZAE94 de Herbaspirillum seropedicae em duas variedades de arroz. A eficiência foi avaliada pela contribuição destas bactérias nos parâmetros agronômicos de produção de grãos, N\%, N-total e proteína bruta dos grãos nas variedades de arroz IR42 e IAC4440. O experimento de inoculação foi conduzido em blocos ao acaso com seis repetições. Para o experimento de reinoculação, as variáveis avaliadas foram semelhantes ao experimento anterior, sendo que a parte aérea das plantas de arroz remanescentes foi retirada e o restante das plantas foi incorporado ao solo. A inoculação da estirpe ZAE 94 foi capaz de suprir até $50 \mathrm{~kg}$ de $\mathrm{N} \mathrm{ha}^{-1}$ dependendo da cultivar utilizada. Não foi observado efeito da reinoculação sobre os parâmetros estudados nas condições testadas, indicando que a inoculação deve ser feita em todos os plantios. Os resultados mostraram-se promissores quanto à utilização da prática de inoculação na cultura do arroz.
\end{abstract}

Palavras-chave: Oryza sativa L.; Fixação biológica de nitrogênio; Plantas não leguminosas.

\begin{abstract}
The study it consisted of evaluating the effect of the inoculation and reinoculação of strain ZAE94 of Herbaspirillum seropedicae in two varieties of rice. The efficiency was evaluated by the contribution of these bacteria in the agronômicos parameters of production of grains, N\%, N-total and rude protein of the grains in the varieties of rice IR42 and IAC4440. The inoculation experiment was lead block-type to perhaps with six repetitions. For the reinoculation experiment, the evaluated variable had been similar to the previous experiment, being that the aerial part of the remaining plants of rice was removed and the remain of the plants was incorporated the ground. The inoculation of lineage ZAE 94 was capable to supply up to $50 \mathrm{~kg}$ of $\mathrm{N} \mathrm{ha}^{-1}$ depending on used cultivating. Effect of the reinoculation on the parameters studied in the tested conditions was not observed, indicating that the inoculation must be made in all the planting. The results had revealed promising how much to the use of the practical one of inoculation in the culture of the rice.
\end{abstract}

Keywords: Oryza sativa L.; Biological nitrogen fixation; Plant non-legumes. 


\section{Resumen}

El estudio consistió en evaluar el efecto de la inoculación y re-inoculación de la cepa ZAE94 de Herbaspirillum seropedicae en dos variedades de arroz. La eficiencia se evaluó por el aporte de estas bacterias en los parámetros agronómicos de producción de grano, N\%, N-total y proteína cruda de grano en las variedades de arroz IR42 e IAC4440. El experimento de inoculación se realizó en bloques al azar con seis repeticiones. Para el experimento de reinculación, las variables evaluadas fueron similares al experimento anterior, con la parte aérea de las plantas restantes de arroz removida y el resto de las plantas incorporadas al suelo. La inoculación de la cepa ZAE 94 fue capaz de suministrar hasta $50 \mathrm{~kg}$ de $\mathrm{N} \mathrm{ha}^{-1}$ dependiendo del cultivar utilizado. No hubo efecto de reinoculación sobre los parámetros estudiados en las condiciones ensayadas, lo que indica que la inoculación debe realizarse en todas las plantaciones. Los resultados mostraron ser prometedores con respecto al uso de la práctica de inoculación en el cultivo de arroz.

Palabras clave: Oryza sativa L.; Fijación biológica de nitrógeno; Plantas no leguminosas.

\section{Introdução}

Puozaa; Jaiswal; Dakora, (2019) afirmam que o nitrogênio é um dos elementos minerais mais essenciais para a produção das plantas, embora se encontre em $78 \%$ na atmosfera, a sua forma de $\mathrm{N}_{2}$ não está prontamente disponível para as plantas, já que a ligação tripla e covalente não pode ser quebrada. Diante disso a Fixação Biológica de Nitrogênio (FBN) realizada por bactérias torna esse processo possível.

Em plantas não leguminosas, o processo não é tão eficiente quanto em leguminosas. Entretanto, várias bactérias que realizam essa fixação constituintes dos gêneros Herbaspirillum, Burkholderia e Azospirillum, têm sido isoladas de plantas como arroz, trigo, milho e sorgo entre outros (Santos et al., 2018; Iyer \& Rajkumar, 2017; Guimarães \& Baldani, 2013; Barbosa et al., 2016).

Resultados da inoculação com Azospirillum mostra uma variabilidade nos efeitos em trigo, arroz, milho e sorgo, onde a média de acréscimo na produção varia de 20 a 30\% (Guimarães et al., 2010; Garcia et al., 2016).

Em arroz, diversas bactérias já foram isoladas associadas aos gêneros Burkholderia, Herbaspirillum, Azospirillum e Pseudomonas e Sphingomonas (Rodrigues et al., 2006; Rodrigues et al., 2008).

Efeitos positivos da inoculação destas bactérias diazotróficas têm sido observados por diversos autores. Guimarães et al. (2010), concluíram que estas bactérias são capazes de aumentar a produção de grãos, proporcionar maior acumulo de nitrogênio e incrementar massa seca. Guimarães e Baldani (2013) e Barbosa et al. (2016) as inoculações em arroz promoverem incrementos de biomassa de parte aérea de $16 \%$ e $113 \%$, respectivamente.

O potencial de utilização dessas bactérias é grande, experimentos de inoculação com estirpes de Herbaspirillum seropedicae mostraram que 17 a 19\% do N acumulado foi derivado da FBN e 11 a 20\% com Burkholderia brasilensis (Baldani et al., 2000). Segundo (Guimarães et al., 2007; Guimarães et al., 2010) em campo dependendo da variedade de arroz o incremento na produção de grãos pode chegar a $62 \%$.

A variedade de arroz IR42, inoculada com as estirpes de Herbaspirillum seropedicae (ZAE 94 ou BR11417) e Burkholderia brasilensis (BR11430) promoveu aumentos na produção de grãos de $38 \%$ e $16 \%$, respectivamente, em relação ao controle não inoculado (Ferreira et al., 2003).

Diante do exposto e a importância da associação com estas bactérias em culturas não leguminosas como arroz, trigo, milho e cana-de-açúcar, e visando diminuir a aplicação de N no Brasil que seria em torno de 2 bilhões de reais ao ano, o uso de bactérias diazotróficas como bioinsumos é viável e deve ser adotada tanto em culturas de plantas leguminosas como não leguminosas. O objetivo deste trabalho foi avaliar o efeito da inoculação e reinoculação da estirpe ZAE94 de H. seropedicae em duas variedades de arroz.

\section{Material e Métodos}

O trabalho é uma análise experimental em campo para avaliação inoculação de bactérias em arroz. 
A análise química da turfa utilizada apresenta as seguintes características: $\mathrm{pH}$ em $\mathrm{H}_{2} \mathrm{O}$ de 3,4, teor de $\mathrm{Al}$ 8,5 $\left(\mathrm{cmol}_{c} \mathrm{dm}^{-3}\right), \mathrm{Ca} 7,1\left(\mathrm{cmol}_{\mathrm{c}} \mathrm{dm}^{-3}\right), \mathrm{Mg} 6,9\left(\mathrm{cmol}_{\mathrm{c}} \mathrm{dm}^{-3}\right), \mathrm{P} 22\left(\mathrm{mg} \mathrm{dm}^{-3}\right), \mathrm{K} 47\left(\mathrm{mg} \mathrm{dm}^{-3}\right)$ e matéria orgânica (MO) de $72\left(\mathrm{~g} \mathrm{~kg}^{-1}\right)$.

A estirpe de Herbaspirillum seropedicae ZAE 94 foi multiplicada em meio Dygs, por 24 horas a $30^{\circ} \mathrm{C}$ sob agitação, e o número de células viáveis foi determinado pelo método do Número Mais Provável (NMP) no meio JNFb (Dobereiner et al., 1995). O número foi de $1,4 \times 10^{9}$ células viáveis $\mathrm{mL}^{-1}$.

A suspensão bacteriana foi inoculada em sacos de polipropileno contendo turfa (previamente seca, moída, esterilizada e pH ajustado, até atingir a umidade inicial desejada. Após a inoculação, a turfa foi mantida por 24 horas a $30^{\circ} \mathrm{C}$ e em seguida armazenada em geladeira a $4{ }^{\circ} \mathrm{C}$.

As variedades de arroz IR42 e IAC4440 foram plantadas no campo experimental da Embrapa Agrobiologia, em um

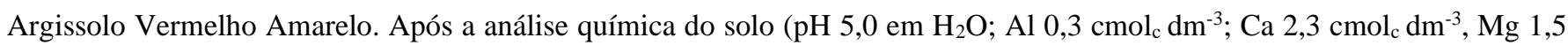
$\mathrm{cmol}_{\mathrm{c}} \mathrm{dm}^{-3} ; \mathrm{P} 14 \mathrm{mg} \mathrm{dm}^{-3} ; \mathrm{K} 84 \mathrm{mg} \mathrm{dm}^{-3}$ ), foi feita a adubação e calagem, segundo recomendações do Manual de Adubação e Calagem para o Rio de Janeiro para a cultura de arroz (Almeida et al., 1988). Como fonte de micronutrientes foi aplicado FTE na quantidade de $14 \mathrm{~kg} \mathrm{ha}^{-1}$.

O plantio do primeiro ano (2009-2010) foi feito com sementes inoculadas, em parcelas com seis linhas, espaçadas 30 cm, com 100 sementes por metro linear. Em 6 blocos ao acaso. Os tratamentos foram: inoculação ou não da estirpe ZAE 94, as variedades IAC4440 e IR42 e 3 doses de $\mathrm{N}$ mineral na forma de sulfato de amônio (20, 50 e $100 \mathrm{Kg} \mathrm{de} \mathrm{N} \mathrm{ha}{ }^{-1}$ ). As doses de

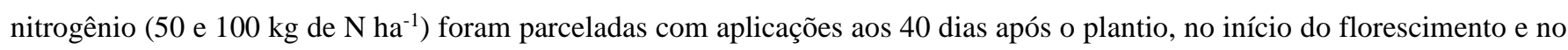
enchimento dos grãos.

No ensaio de reinoculação (2010-2011), a parte aérea das plantas de arroz remanescente do ano anterior, foi retirada e o restante das plantas foi incorporado ao solo. Após a análise química do Argissolo Vermelho Amarelo (pH 5,0 em $\mathrm{H}_{2} \mathrm{O} ; \mathrm{Al}$ $0,2 \mathrm{cmol}_{\mathrm{c}} \mathrm{dm}^{-3} ; \mathrm{Ca} 2,1 \mathrm{cmol}_{\mathrm{c}} \mathrm{dm}^{-3}, \mathrm{Mg}_{1,1} \mathrm{cmol}_{\mathrm{c}} \mathrm{dm}^{-3} ; \mathrm{P} 4,7 \mathrm{mg} \mathrm{dm}^{-3} ; \mathrm{K} \mathrm{70,4} \mathrm{mg} \mathrm{dm}{ }^{-3}$ ), foi feita a correção de acordo com a necessidade da cultura.

As características avaliadas foram: produção de grãos, $\mathrm{N} \%$ e $\mathrm{N}$-total dos grãos e proteína bruta dos grãos, calculada pelo N-Kjeldahl multiplicado pelo fator de correção de 5,95 (Juliano, 1985).

A comparação das médias foi feita utilizando o teste estatístico LSD a 5\% de probabilidade.

Para o experimento de reinoculação, as variáveis avaliadas foram semelhantes ao experimento anterior. Entretanto, na comparação das médias foi utilizado o teste estatístico Scott-Knott a 5\% de probabilidade. Para aplicação dos testes foi utilizado o programa SISVAR (Ferreira, 2011).

\section{Resultados e Discussão}

A máxima resposta à inoculação da variedade IR42 foi observada com H. seropedicae (ZAE 94), adicionado de $20 \mathrm{~kg}$ de $\mathrm{N} \mathrm{ha}^{-1}$. Este tratamento acrescentou em $88 \%$ a produção de grãos em relação ao tratamento não inoculado e não adubado, $14 \%$ em relação ao tratamento que recebeu somente a inoculação e 20,5\% em relação ao tratamento que recebeu $20 \mathrm{~kg}$ de $\mathrm{N}$ ha $^{-1}$ (Tabela 1).

Em relação ao tratamento não inoculado e não adubado, a inoculação da estirpe estudada aumentou a produção de grãos em torno de $65 \%$. Com base nesses resultados pode-se concluir que a inoculação desta estirpe pode contribuir com mais de $20 \mathrm{Kg}$ de $\mathrm{N} \mathrm{ha}^{-1}$ na variedade IR42 (Tabela 1). 
Tabela 1. Produtividade de grãos, N-total e acúmulo de proteínas dos grãos de arroz da variedade IR42 inoculada com a

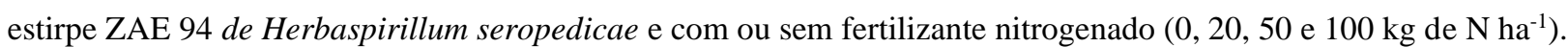

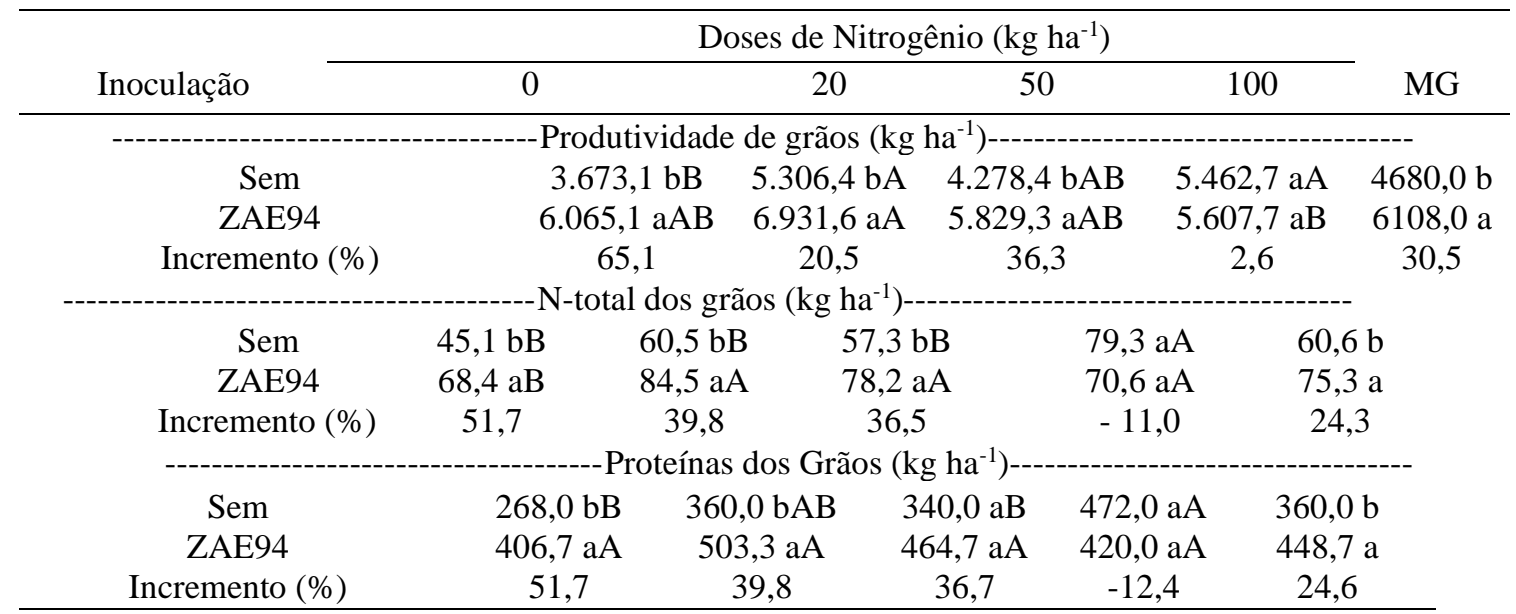

As letras maiúsculas separam as médias dentro das linhas e as minúsculas separam as médias dentro de cada coluna. Letras iguais não diferem entre si pelo teste LSD a 5\% de significância. Médias de 6 repetições. MG: Média Geral dos tratamentos inoculado e não inoculado. Fonte: Autores.

Já na variedade IAC4440 foi observado que a produção de grãos da inoculação com adubação não diferiu estatisticamente das testemunhas adubadas, exceto quando utilizada a dose de $100 \mathrm{~kg}$ de $\mathrm{N} \mathrm{ha}^{-1}$. A inoculação da estirpe ZAE 94 acrescidos de $20 \mathrm{~kg}$ de $\mathrm{N} \mathrm{ha}^{-1}$ incrementou a produção em 8 e 18\%, em relação à testemunha absoluta e testemunha

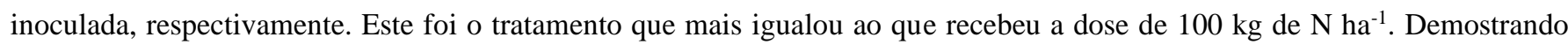
assim que a máxima resposta à adubação, na variedade IAC440, foi obtida na dose de $100 \mathrm{~kg} \mathrm{de} \mathrm{N}$ ha $^{-1}$ (Tabela 2).

Tabela 2. Produtividade de grãos, N-total e acúmulo de proteínas dos grãos de arroz da variedade IAC 4440 inoculada com a estirpe ZAE 94 de Herbaspirillum seropedicae e com ou sem fertilizante nitrogenado (0, 20, 50 e $100 \mathrm{~kg}$ de $\mathrm{N}$ ha-1).

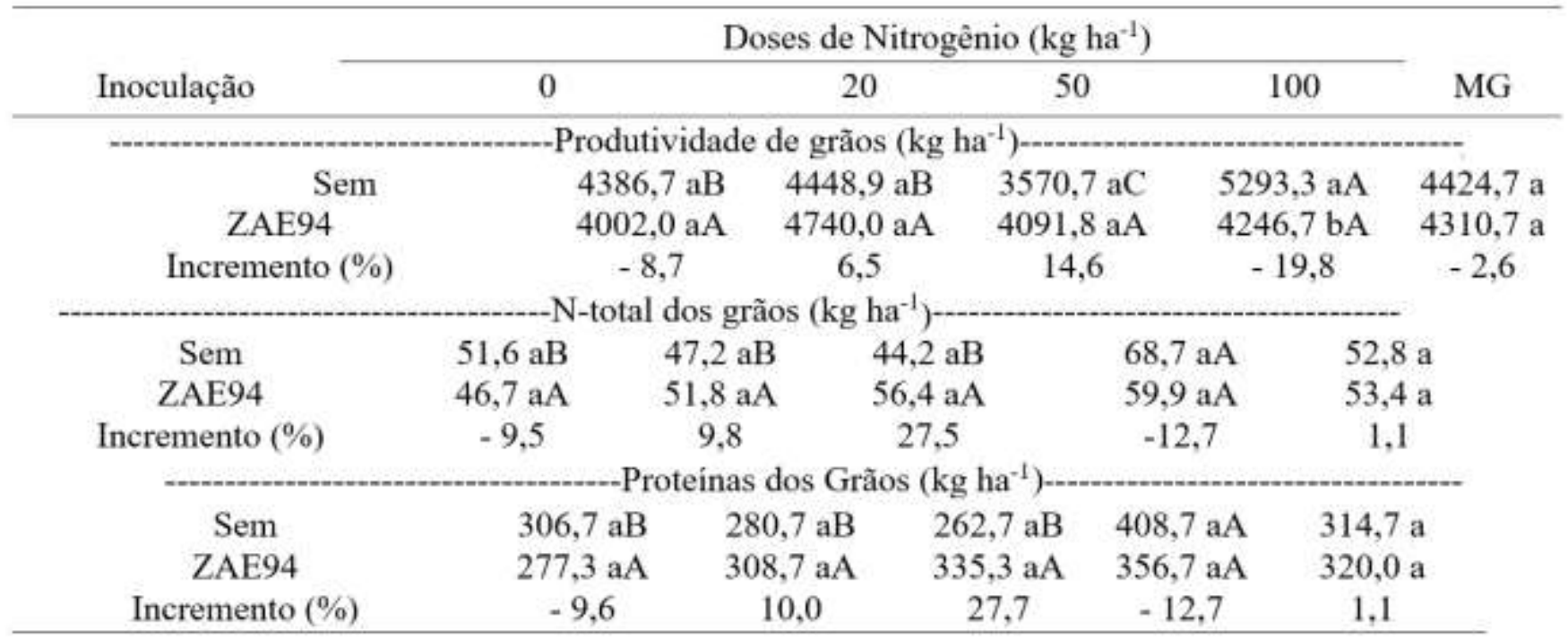

As letras maiúsculas separam as médias dentro das linhas e as minúsculas separam as médias dentro de cada coluna. Letras iguais não diferem entre si pelo teste LSD a 5\% de significância. Médias de 6 repetições. MG: Média Geral dos tratamentos inoculado e não inoculado. Fonte: Autores.

O efeito positivo da inoculação, com bactérias diazotróficas, também foi observado por Rodrigues et al. (2015), Viana et al. (2016) quando inocularem Herbaspirillum seropedicae ZAE 94, 17 B e 37 C associadas com diferentes doses de N em arroz variedade Tropical BRS, incrementaram 9,4 e 3,3\% na altura, 14,4\% no número de perfilhos, 98\% nas plantas secas e $3,2 \%$ no peso da massa seca do grão, em relação ao tratamento controle, a adição de $60 \mathrm{~kg} \mathrm{ha}^{-1}$ de $\mathrm{N}$, resultou em um aumento na produção de $174,4,159,4$ e $208,5 \%$, respectivamente. 
Diferentemente do estudo, Gitti et al. 2012; Goes 2012; Chaves et al., 2016; Garcia 2017; Garé et al. 2017 em arroz inoculado com A. brasilense não observaram efeito da inoculação no crescimento do arroz.

Longhini et al., (2015) observaram que a inoculação de sementes com A. brasilense aumentou a altura das plantas e a produtividade dos grãos em milho, Alves et al., (2020) notou que a inoculação de plantas com ZAE94 contribuiu com cerca de $30 \%$ do $\mathrm{N}$ acumulado nas plantas inoculadas e também aumentou o comprimento e volume da raiz, além da área foliar.

As avaliações dos teores de nitrogênio total e proteínas total mostraram, nas duas variedades, que a inoculação promoveu aumentos porém foi dependente da variedade e dose de N. Para a variedade IR42, a inoculação promoveu aumentos de até $52 \%$ dependendo da dose de nitrogênio utilizada. Sendo que, a inoculação com $20 \mathrm{~kg}$ de $\mathrm{N} \mathrm{ha}^{-1}$, incrementou $88 \%$ em relação à testemunha absoluta, 24\% em relação ao tratamento que recebeu somente a inoculação e 39,4\% em relação ao tratamento que recebeu $20 \mathrm{~kg}$ de $\mathrm{N} \mathrm{ha}^{-1}$ (Tabelas 1 e 2).

A produção de grãos na variedade IAC4440 seguiu o mesmo padrão anterior. Portanto, nesta variedade, os tratamentos inoculado e inoculado mais a adubação não diferiram estatisticamente das testemunhas adubadas. A inoculação da estirpe ZAE 94 acrescidos de $20 \mathrm{~kg}$ de $\mathrm{N} \mathrm{ha}^{-1}$ mostrou uma tendência em aumentar esses parâmetros em 0,6 e 11\%, (Tabela 2).

A variedade IAC 4440, a inoculação da ZAE 94 aumentou em até 15\% o nitrogênio acumulado nos grãos. Guimarães \& Baldani (2013) ao avaliar os efeitos da inoculação de Herbaspirillum spp. e Burkholderia spp. também encontraram incrementos de até $54 \%$ na produção de grãos em função da inoculação com bactérias diazotróficas.

A análise de nitrogênio total e proteína total dos grãos na variedade IR42 mostrou que a inoculação da estirpe ZAE 94 proporcionou resultados superiores ao tratamento que não recebeu inoculação e foram estatisticamente iguais à testemunha que

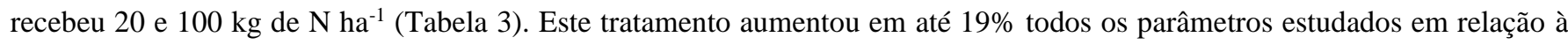
testemunha não inoculada. Resultados semelhantes foram encontrados por Ferreira et al. (2010) trabalhando com arroz irrigado em casa de vegetação.

Tabela 3. Produção de grãos, nitrogênio total e proteína bruto total dos grãos das plantas de arroz da variedade IR42 inoculadas ou não com a estirpe ZAE 94 de Herbaspirillum seropedicae e com ou sem fertilizante nitrogenado (0, 20, 50 e 100 $\mathrm{kg}$ de $\mathrm{N} \mathrm{ha}^{-1}$ ) e tratamentos de reinoculação.

\begin{tabular}{|c|c|c|c|c|}
\hline Tratamentos & PG & & N- total & PTG \\
\hline & & & ---kg ha-1--- & \\
\hline Não Inoc. & 3423,33 & $\mathrm{~b}$ & $42,00 \mathrm{a}$ & $125,28 \mathrm{a}$ \\
\hline 20 kg N.ha- ${ }^{-1}$ & 3966,67 & a & 50,67 a & $150,42 \mathrm{a}$ \\
\hline $50 \mathrm{~kg} \mathrm{~N} \cdot \mathrm{ha}^{-1}$ & 3006,67 & $\mathrm{~b}$ & $42,00 \mathrm{a}$ & $125,47 \mathrm{a}$ \\
\hline $100 \mathrm{~kg} \mathrm{~N} \cdot \mathrm{ha}^{-1}$ & 3346,67 & a & $48,00 \mathrm{a}$ & $143,70 \mathrm{a}$ \\
\hline $\mathrm{T} 1$ & 4046,67 & $\mathrm{a}$ & 50,00 a & $148,50 \mathrm{a}$ \\
\hline Inoc $+20 \mathrm{~kg} \mathrm{~N} \cdot \mathrm{ha}^{-1}$ & 3640,00 & $\mathrm{a}$ & 44,00 a & $132,86 \mathrm{a}$ \\
\hline Inoc $+50 \mathrm{~kg} \mathrm{~N} \cdot \mathrm{ha}^{-1}$ & 4041,33 & $\mathrm{a}$ & 47,33 a & $140,96 \mathrm{a}$ \\
\hline Inoc +100 kg N.ha ${ }^{-1}$ & 3180,00 & $\mathrm{~b}$ & $42,00 \mathrm{a}$ & $130,69 \mathrm{a}$ \\
\hline $\mathrm{T} 2$ & 3469,33 & $\mathrm{~b}$ & 44,00 a & $131,64 \mathrm{a}$ \\
\hline Reinoculação & 3686,67 & $\mathrm{a}$ & 48,67 a & $144,06 \mathrm{a}$ \\
\hline $\mathrm{CV}(\%)$ & 10,4 & & 13,4 & 13,52 \\
\hline
\end{tabular}

Inoc: Tratamentos inoculados com a estirpe ZAE 94; PG: Produção Grãos; PTG: Proteínas Total Grãos , T1= Sem inoculação no $1^{\circ}$ ano e Inoculado no $2^{\circ}$ ano. T2: Inoculado no $1^{\circ}$ ano e não Inoculado no $2^{\circ}$ ano. Letras iguais não diferem entre si pelo teste Scott-Knott a 5\% de significância. Médias de 6 repetições. Fonte: Autores. 
Não foram observadas diferenças significativas entre (T1) e a reinoculação na variedade IR42. Estes tratamentos foram estatisticamente iguais à testemunha que recebeu $20 \mathrm{~kg} \mathrm{de} \mathrm{N} \mathrm{ha}^{-1}$ e superiores aos tratamentos que não recebeu inoculação.

A análise de produção, nitrogênio total e proteína total dos grãos na IAC4440, mostrou que a inoculação proporcionou resultados superiores aos tratamentos sem inoculação, e foram estatisticamente iguais a testemunha com 20 e $50 \mathrm{~kg}$ de N.ha-1 (Tabela 4). A inoculação e reinoculação aumentaram a produção, nitrogênio total e proteína total dos grãos em 40, 51 e 45\%, respectivamente, em relação à testemunha não inoculada. Estes resultados indicam que a inoculação e reinoculação podem contribuir com até $50 \mathrm{~kg}_{\text {de }} \mathrm{N}^{-1}$ na IAC4440.

Tabela 4. Produção de grãos, nitrogênio total e proteína total dos grãos das plantas de arroz da variedade IAC4440 inoculadas ou não com a estirpe ZAE 94 de Herbaspirillum seropedicae e com ou sem fertilizante nitrogenado $(0,20,50$ e $100 \mathrm{~kg}$ de $\mathrm{N}$ $\mathrm{ha}^{-1}$ ) e tratamentos de reinoculação.

\begin{tabular}{|c|c|c|c|}
\hline Tratamentos & PG & $\mathrm{N}$ - total & $\begin{array}{l}\text { PTG } \\
\end{array}$ \\
\hline \multicolumn{4}{|c|}{--- kg ha'--- } \\
\hline Não Inoc. & $3143,33 \mathrm{~b}$ & $31,00 \mathrm{~b}$ & $186,07 \mathrm{c}$ \\
\hline 20 kg N.ha ${ }^{-1}$ & $4088,89 \mathrm{a}$ & $51,00 \mathrm{a}$ & $303,48 \mathrm{a}$ \\
\hline 50 kg N.ha ${ }^{-1}$ & $4548,89 \mathrm{a}$ & $57,33 \mathrm{a}$ & $340,71 \mathrm{a}$ \\
\hline 100 kg N.ha ${ }^{-1}$ & $3393,33 \mathrm{~b}$ & 42,67 a & $252,80 \mathrm{~b}$ \\
\hline $\mathrm{T} 1$ & $4115,56 \mathrm{a}$ & $46,00 \mathrm{a}$ & $272,90 \mathrm{~b}$ \\
\hline Inoc +20 kg N.ha ${ }^{-1}$ & $3377,78 \mathrm{~b}$ & $38,67 \mathrm{~b}$ & $222,59 \mathrm{c}$ \\
\hline Inoc +50 kg N.ha ${ }^{-1}$ & $3486,67 \mathrm{~b}$ & $50,00 \mathrm{a}$ & $298,01 \mathrm{a}$ \\
\hline Inoc $+100 \mathrm{~kg} \mathrm{~N} \cdot \mathrm{ha}^{-1}$ & $3151,11 \mathrm{~b}$ & 46,67 a & $278,33 \mathrm{~b}$ \\
\hline $\mathrm{T} 2$ & $3131,33 \mathrm{~b}$ & $35,67 \mathrm{~b}$ & $212,03 \mathrm{c}$ \\
\hline Reinoculação & $4393,33 \mathrm{a}$ & $47,00 \mathrm{a}$ & $272,56 \mathrm{~b}$ \\
\hline CV (\%) & 10,4 & 13,4 & 11,8 \\
\hline
\end{tabular}

Inoc: Tratamentos inoculados com a estirpe ZAE 94; PG: Produção Grãos; PTG: Proteínas Total Grãos, T1= Sem inoculação no $1^{\circ}$ ano e Inoculado no $2^{\circ}$ ano. T2: Inoculado no $1^{\circ}$ ano e não Inoculado no $2^{\circ}$ ano. Letras iguais não diferem entre si pelo teste Scott-Knott a $5 \%$ de significância. Médias de 6 repetições. Fonte: Autores.

A produção, nitrogênio total e proteínas dos grãos, no experimento de reinoculação, em ambas variedades de arroz, mostraram que a inoculação de ZAE 94 se faz necessária em todos os anos de plantio, já que a reinoculação foi estatisticamente igual ao tratamento que recebeu a inoculação desta estirpe no segundo ano (T1) e estatisticamente superior aos tratamentos não inoculado e que recebeu inoculação somente no primeiro ano (T2).

Os resultados obtidos nestes experimentos demonstram que a inoculação, com a estirpe ZAE 94, é uma prática importante e que pode contribuir com parte do nitrogênio necessário ao desenvolvimento da cultura de arroz, dependendo das variedades e condições utilizadas.

\section{Conclusões}

A inoculação da estirpe ZAE 94 foi capaz de suprir até $50 \mathrm{~kg} \mathrm{de} \mathrm{N} \mathrm{ha}^{-1}$ dependendo do cultivar utilizado.

Não foi observado efeito da reinoculação sobre os parâmetros estudados, indicando que a inoculação deve ser feita em todos os plantios. 
Trabalhos posteriores pode ser testado diferentes bactérias para inoculação buscando elucidar a associação com a cultura, épocas de plantio e diferentes doses de nitrogênio também podem ser associadas a diferentes variedades para fortalecer a resposta da inoculação positiva no crescimento das plantas e produtividade.

\section{Agradecimentos}

\section{À UESB pelo auxílio (AUXPPI-PAR 2018).}

\section{Referências}

Alves, M. V.; Nesi, C. N.; Naibo, G.; Barreta, M. H.; Lazzari, M.; JúnioR, A. F.; Skoronski, E. Corn seed inoculation with Azospirillum brasilense in different nitrogen fertilization management. Revista Brasileira de Ciências Agrárias (Agrária), v. 15, n. 3, 2020.

BaldanI, V. L. D., Baldani, J. I., Dobereiner, J. Inoculation of rice plants with endophytic diazotrophs Herbaspirillum seropedicae and Burkholderia spp. Biol Fertil Soils, v.30, p.485-491, 2000.

Barbosa, A. M.; Pancieiro, L. A.; Catuchi, T. A.; Araujo, F. F.; Tiritan, C. S.; Silva, M. A. Respostas de cultivares de arroz a formas de inoculação com Azospirillum brasilense. Acta Iguazu, v.5, n.3, p. 99 - 110, 2016.

Chaves, J. S.; Miranda, A. F. M.; Santana, A. S.; Rodríguez, C. A.; Silva, E. S. Eficiência da inoculação na cultura do arroz (Oryza Sativa L.) no sul do estado de roraima. Revista Eletrônica Ambiente, Gestão e Desenvolvimento, v. 9, n. 2, 2016

Dobereiner, J.; Baldani, V. L. D.; Baldani, J. I. Como isolar e identificar bactérias diazotróficas de plantas não leguminosas. Brasília: EMBRAPASPI:Itaguaí, RJ: EMBRAPA-CNPAB, 1995, 60p.

Ferreira, D. F. Sisvar: A computer statistical analysis system. Ciência e Agrotecnologia, v.35, p.1039-1042, 2011.

Ferreira, J. S.; Baldani, J.I.; Baldani, V. L. D. Seleção de inoculantes à base de turfa contendo bactérias diazotróficas em duas variedades de arroz. Acta Scientiarum. Agronomy, v. 32, n. 1, p. 179-185, 2010.

Garcia, N. F. S.; Arf, O.; Portugal, J. R.; Peres, A. R.; Rodrigues, M.; Penteado, M. S. Doses and application methods of Azospirillum brasilense in irrigated upland rice. Revista Brasileira de Engenharia Agrícola e. Ambiental, v.20, n.11, p.990-995, 2016.

Garcia, N. F. S. Culturas antecessoras e inoculação de Azospirillum brasilense em arroz de terras altas e feijão de inverno em sucessão inoculado com Rhizobium tropici. 2017. Dissertação (Mestrado) -Curso de Agronomia, Faculdade de Engenharia -Unesp -Campus de Ilha Solteira -SP.

GARÉ, L. M.; BUZO, F. S.; ARF, O.; PORTUGAL, J. R.; SILVEIRA, T. L. S.; MEIRELLES, F. C. influence of thidiazuron and inoculation with Azospirillum brasilense in the growth and productivity of highland rice. Revista Brasileira de Engenharia de Biossistemas, Tupã, São Paulo, Brazil, v. 11, n. 4, p. 326-339, 2017.

Gitti, D. C.; Arf, O.; Portugal, J. R.; Corsini, D. C. D. C.; Rodrigues, R. A. F.; Kaneko, F. H. Coberturas vegetais, doses de nitrogênio e inoculação de sementes com Azospirillum brasilense em arroz de terras altas no sistema plantio direto. Bragantia, v.71, n.4, 509-517, 2012.

Goes, R. Inoculação de Sementes com azospirillum brasilense e doses de n mineral em arroz de terras altas irrigado por aspersão. $30 f$. Relatório (Mestrado em Agronomia) -Faculdade de Engenharia, Universidade Estadual Paulista, Ilha Solteira, 2012.

Guimarães, S. L.; Baldani, V. L. D. Produção de arroz inoculado com bactérias diazotróficas marcadas com resistência induzida ao antibiótico estreptomicina. Revista de Ciências Agrárias Amazonian Journal of Agricultural and Environmental Sciences, v. 56, n. 2, p. 152-132, 2013.

Guimarães, S. L.; Campos, D. T. S.; Baldani, V. L. D.; Jacob-Neto, J. Bactérias diazotróficas e adubação nitrogenada em cultivares de arroz. Revista Caatinga, v. 23, n. 4, p. 32-39, 2010 .

Iyer, B.; Rajkumar, S. Host specificity and plant growth promotion by bacterial endophytes. Current Research in Microbiology and biotechnology, v. 5, n. 2, p. 1018- 1030, 2017.

Juliano, B. O. Polysaccharides, proteins and lipids of rice. In: JULIANO, B. O. (Ed.). Rice: chemistry and technology. 2nd ed. St. Paul: American Association of Cereal Chemists. p. 59-175, 1985.

Longhini, V. Z.; Souza, W. C. R. D.; Andreotti, M.; Soares, N. D. A.; Costa, N. R. Inoculation of diazotrophic bacteria and nitrogen fertilization in topdressing in irrigated corn. Revista Caatinga, v. 29, p. 338-347, 2016.

Puozaa, D. K.; Jaiswal, S. K.; Dakora, F. D. Phylogeny and distribution of Bradyrhizobium symbionts nodulating cowpea (Vigna unguiculata L. Walp) and their association with the physicochemical properties of acidic African soils. Systematic and Applied Microbiology, v. 42, p. 403-414, 2019.

Rodrigues, M., Arf, O., Garcia, N. F. S., Portugal, J. R., Barbieri, M. K. F.Inoculação de sementes com Azospirillum brasilensee adubação nitrogenada em cultivares de arroz de terras altas irrigados por aspersão.Enciclopédia Biosfera,Goiânia, v. 11, n.21, p.1234-1241, jun. 2015.

Rodrigues, E. P.; Rodrigues, L. S.; Oliveira, A. M. O.; Baldani, V.L.D.; Teixeira, K.R.S.; Urquiaga,S..; Reis,V.M. Azospirillum amazonense inoculation: effects on growth, yeld and N2 fixation of rice (Oryza sativa L.). Plant and Soil, The Hague, NL, v.302, n.1-2, p. 249-261, jan. 2008. 
Research, Society and Development, v. 10, n. 16, e458101623873, 2021

(CC BY 4.0) | ISSN 2525-3409 | DOI: http://dx.doi.org/10.33448/rsd-v10i16.23873

Rodrigues, L. S.; Baldani, V. L. D.; Reis, V. M.; Baldani, J. I. Diversidade de bactérias diazotróficas endofíticas dos gêneros Herbaspirillum e Burkholderia na cultura do arroz inundado. Pesquisa Agropecuária Brasileira, v. 41, n. 2, p. 275-284, 2006.

Santos, W. F.; Afférri, F. S.; Pelúzio, J. M.; Sodré, L. F.; Rotili, E. A.; Cerqueira, F. B.; Ferreira, T. P. S. Genetic diversity in maize under nitrogen restriction conditions. Journal of Bioenergy and Food Science, v. 5, n. 2, p. 44-53, 2018.

Viana, T.O.; Santos, J. S.; Manfredi, C.; Moreira, R. V. S.; Baldani, V. L. D.; Ferreira, J. S. Isolation and inoculation of diazotrophic bacteria in rice (Oryza sativa L.) grown in Vitoria da Conquista-BA. African Journal of Agricultural Research, v. 10, n. 29, p. 2847-2854, 2015. 